\section{Hartnup disease}

By M. D. Mrune. (Medical Unit, Westminster Medical School, London, S.W. 1)

Hartnup disease, named after the surname of the first known affected family (Baron, Dent, Harris, Hart \& Jepson, 1956) is characterized clinically by a pellagrous rash, and in some patients neuropsychiatric abnormalities. Four hereditary conditions, all autosomal recessive diseases, involve deficient transport of groups of amino acids or of monosaccharides in the proximal renal-tubule cells and the jejunal mucosa, i.e. glucose-galactose malabsorption (Laplane et al. 1962; Lindquist \& Meeuwisse, 1962), cystinuria (Dent \& Rose, 1951; Milne, Asatoor, Edwards \& Loughridge, 1961) affecting the dibasic amino acids cystine, lysine, arginine and ornithine, iminoprolinuria (Goodman, McIntyre \& O'Brien, 1967; Scriver, 1968) affecting glycine, proline and hydroxyproline, and Hartnup disease with deficient transport of a large number of neutral amino acids (Baron et al. 1956; Milne, Crawford, Girao \& Loughridge, 1960). Defective renal-tubular transport in Hartnup disease is readily proven by clearance determinations. Clearances of alanine, serine, threonine, asparagine, glutamine, valine, leucine, isoleucine, phenylalanine, tyrosine, tryptophan, histidine and citrulline are all considerably above normal values but plasma concentrations are normal or low (Cusworth $\&$ Dent, 1960). Other parameters of renal-tubular function are normal, and there is no proteinuria. Defective transport of these amino acids in the small intestine is less easily proven, but many investigators have now shown that (a) plasma concentrations after oral loading of several of these amino acids are abnormally low, although they are normal after intravenous administration, (b) many of the affected amino-acids are present in faeces from cases of the disease, and (c) bacterial degradation products of unabsorbed amino acids are present in excess in both faeces and urine (Milne et al. 1961; Scriver, 1965).

Tryptophan has been studied in most detail because of its relation to clinical pellagra. A high proportion of dietary tryptophan in Hartnup disease is wasted as a result of excess urinary and faecal losses of the amino acid, and conversion by colonic bacteria to derivatives, such as indole and indolylacetic acid, that are nutritionally valueless.

Jepson (1966) listed 23 known affected patients. An additional 13 cases have since been described (Dauth, Dietel \& Erbert, 1966; Nielsen, Vedro \& Zimmermann-Nielsen, 1966; Wong \& Pillai, 1966; Seakins \& Ersser, 1967; Pomeroy, Efron, Dayman \& Hoefnagel, 1968; F. Navab, personal communication). The family trees are typical of autosomal recessive heredity. Twenty-two affected families have been described with a total number of offspring of 80. Theoretically, by applying the Bernstein (1929) correction for families which are unrecognized because no children are affected, a total average of 31.3 individuals would be expected to be homozygotes for Hartnup disease. The observed figure is 36, which is not statistically different from that expected $(0 \cdot 2>P>0 \cdot 1)$. Twenty-three of the reported cases have been females and 13 males. The discrepancy from the expected equal number of each sex is again not significant $(0 \cdot 3>P>0 \cdot 2)$. The percentage of consanguinity in the parents of cases is $18 \%$, a value typical of a rare recessive gene. There is still doubt whether the heterozygotes for the condition are in any way abnormal. Certainly their urinary amino acid excretion is perfectly normal. Wong \& Pillai (1966) claim that they have a slightly impaired efficiency of tryptophan absorption from the gut, plasma concentrations being significantly lower than controls $2 \mathrm{hr}$. after ingestion of L-tryptophan at a dosage of $0 \cdot 1 \mathrm{~g} . / \mathrm{kg}$. body wt. There is an unusually high incidence of photosensitivity in apparently non-affected relatives (Weyers \& Bickel, 1958; Halvorsen \& Halvorsen, 1963; Pomeroy et al. 1968) suggesting some degree of nicotinamide deficiency. There is, therefore, suggestive evidence of somewhat decreased intestinal amino-acid transport in heterozygotes but no urinary abnormality.

The most common presenting symptom is the pellagrous rash, which occurred in at least 26 patients, the remainder being discovered by aminoacid chromatography of urine from asymptomatic sibs and in three cases by routine screening. In over $90 \%$ of clinical cases the rash first occurred during the first 10 years of life, and the incidence from 0 to 5 was about twice that from 5 to 10 years. The rash is in all respects similar to that of dietary pellagra and is as rapidly cured by adequate nicotinamide therapy. Diets low in tryptophan and nicotinamide undoubtedly predispose to development of the typical rash: one patient had lived chiefly on corn flakes (Henderson, 1958), and another only developed the rash when she visited Africa and had a diet including large amounts of maize (F. Navab, personal communication). Hartnup disease merely decreases the efficiency of tryptophan utilization and metabolic conversion into nicotinamide, and therefore increases the threshold at which diets become inadequate to provide enough nicotinamide for bodily requirements.

The causation of the neuropsychiatric symptoms and signs of the disease has been more controversial. These include headaches, poor concentration, memory defects, minimal or inadequate emotional response, nystagmus, ataxia, weakness of the limbs giving rise to sudden 'collapsing attacks', spastic 
paraplegia, and severe electroencephalographic abnormalities. Two main explanations have been advanced: $(a)$ they are equivalent to the neuropsychiatric effects of dietary pellagra, being due to nicotinamide deficiency of the central nervous system; (b) they are due to the toxic effects of metabolites produced by bacterial action of unabsorbed amino acids within the colon.

The available evidence is more in favour of the former explanation, but the latter cannot be excluded in every case. Neuropsychiatric effects are less common than in pellagrous dermatitis, having been described in only 16 cases of the disease. They are usually worse during exacerbations of the dermatitis, a strong indication that they are of similar aetiology. The psychiatric symptoms are relieved as rapidly as is the dermatitis by adequate nicotinamide therapy, although the more severe neurological abnormalities may prove more resistant. The neuropsychiatric effects described in dietary pellagra are very similar, and occur in approximately the same proportion of affected patients.

In addition to lack of tryptophan and secondary nicotinamide deficiency, Hartnup disease causes some generalized nutritional defects, presumably due to poor absorption and excess urinary loss of essential amino acids, including the three branchedchain acids, threonine and phenylalanine. Colliss, Levi \& Milne (1963) reported that patients with Hartnup disease were of reduced stature, the mean height being about $5 \mathrm{~cm}$. less than the normal average $(P<0.05)$. Data from eight more cases are now available, and, though the conclusion remains the same, the revised $P$ value is $<0.001$. Visakorpi, Hjelt, Lahikainen \& Ohmans (1964) recorded a case with particularly severe nutritional effects. The height of the patient when aged 9 years was $114 \mathrm{~cm}$., and liver biopsy showed severe fatty degeneration similar to that found in kwashiorkor. Five years later, the height had only increased by $4 \mathrm{~cm}$., there was infantilism, and the patient died from hepatic and myocardial failure.

In conclusion, Hartnup disease, although rare, is of disproportionate importance, as it has features of great physiological and nutritional interest. Further studies may help to solve problems of amino acid transport, of protein malnutrition, and of nicotinamide deficiency.

Baron, D. N., Dent, C. E., Harris, H., Hart, E. W. \& Jepson, J. B. (1956). Lancet, ii, 421.

Bernstein, F. (1929). Variations und Erblichkeitsstatistik, Berlin.

Colliss, J. E., Levi, A. J. \& Milne, M. D. (1963). Brit. med. J. i, 590 .

Cusworth, D. C. \& Dent, C. E. (1960). Biochem. J. 74, 550.

Dauth, K. H., Dietel, K. \& Erbert, W. (1966). Z. Kinderheilk. 95, 103.
Dent, C. E. \& Rose, G. A. (1951). Quart. J. Med., N.S., 20, 205.

Goodman, S. I., McIntyre, C. A., jun. \& O'Brien, D. (1967). J. Pediat. 71, 246.

Halvorsen, K. \& Halvorsen, S. (1963). Pediatrics, N.Y., 31, 29.

Henderson, W. (1958). Arch. Dis. Childh. 33, 114.

Jepson, J. B. (1966). Hartnup Disease. In The Metabolic Basis of Inherited Disease, 2nd ed. Ed. by Stanbury, J. B., Wyngaarden, J. B. \& Fredrickson, D. S. New York: McGraw-Hill Book Co.

Laplane, R., Polonovski, C., Etienne, M., Debray, P., Lods, J. C. \& Pissaro, B. (1962). Arch. franç. Pédiat. 19, 895.

Lindquist, B. \& Meeuwisse, G. W. (1962). Acta paediat., Stockh., 51, 574.

Milne, M. D., Asatoor, A. M., Edwards, K. D. G. \& Loughridge, L. W. (1961). Gut, 2, 323.

Milne, M. D., Crawford, M. A., Girao, C. B. \& Loughridge, L. W. (1960). Quart. J. Med., N.S., 29, 407.

Nielsen, E. G., Vedro, S. \& Zimmermann-Nielsen, C. (1966). Dan. med. Bull. 13, 155.

Pomeroy, J., Efron, M. L., Dayman, J. \& Hoefnagel, D. (1968). New Engl. J. Med. 278, 1214.

Scriver, C. R. (1965). New Engl. J. Med. 273, 530.

Scriver, C. R. (1968). J. clin. Invest. 47, 823.

Seakins, J. W. T. \& Ersser, R. S. (1967). Arch. Dis. Childh. $42,682$.

Visakorpi, J. K., Hjelt, L., Lahikainen, T. \& Ohmans, S. (1964). Ann. paediat. fenn. 10, 42.

Weyers, H. \& Bickel, H. (1958). Klin. Wschr. 36, 893.

Wong, P. W. K. \& Pillai, P.M. (1966). Arch. Dis. Childh.41, 383.

\section{Histidinaemia}

By J. W. T. Seakins and J. B. Holton. (Institute of Child Health, London, W.C. 1, and Southmead Hospital, Bristol)

Histidinaemia is a rare inborn error of metabolism, first described by Ghadimi, Partington \& Hunter (1961). In all about 20 cases have been reported in the literature (Ghadimi \& Zischka, 1967), and additionally four patients in two unrelated families are known to one of the authors (J. W. T. Seakins, unpublished work). It is caused by the absence or deficiency of the enzyme histidase (L-histidine ammonia-lyase, EC 4.3.1.3), which is normally present in skin (Zannoni \& $\mathrm{La} \mathrm{Du}, 1963$ ) and liver (Auerbach, DiGeorge \& Carpenter, 1967).

The clinical manifestations of histidinaemia are variable; indeed, one investigator has said histidinaemia is a 'biochemical defect in search of a disease' (quoted in Auerbach et al. 1967). About half the patients have a mild degree of mental retardation; the remainder have normal intelligence. A delay in the onset of speech or a speech defect has been reported in half of the patients and may or may not be associated with mental retardation. If there is a connexion between the biochemical disorder and the clinical manifestations, the greater variability 